\title{
An angle speed and thrust relationship of the quadcopter rotor
}

\author{
Al Al, Arfita Yuana Dewi, Antonov Bachtiar, Dwi Harinita \\ Departement of Electrical Engineering, FTI ITP Padang, Indonesia
}

\section{Article Info}

Article history:

Received Sep 17, 2018

Revised Nov 22, 2018

Accepted Dec 6, 2018

Keywords:

Rotor thrust coefficient

\begin{abstract}
Utilizing Quadcopter were still many obstacles such as; plane easy to fall; the battery was not durable; vulnerable to weather conditions and others. The research and development have grown to improve aircraft facilities and capabilities. Many parameters related to aircraft lift capability factors; fly long; flying high; type of motor; the type of propeller: including the sensors and control systems used. This study was to find the relationship between changes in the BLDC motor voltage source to the rotor angle velocity $(\omega)$; rotor speed of the rotor lift $(\mathrm{Ft})$; wind speed to rotor lift; push the following rotor $(\mathrm{Ct})$. Empirical testing was conducted in the laboratory to find the relationship of these parameters. The results data show that; the lift power generated with rotational speed was not proportional, non-linearity occurs when the rotor was released from the self and starts pulling the strain gauge when the rotation speed reaches around $65 \mathrm{rps}$. Once the rotation speed of the rotor is able to reach up to 1.5 Newton lift, then the thrust rising trend sharply increasing in increasing of the rotor speed. A motorist had $1200 \mathrm{KV}$ and blade with a radius of $0.12 \mathrm{~m}$, then obtained thrust $(\mathrm{Ct})$ of 1.732 .
\end{abstract}

Copyright (c) 2019 Institute of Advanced Engineering and Science. All rights reserved.

Corresponding Author:

$\mathrm{Al} \mathrm{Al}$,

Departement of Electrical Engineering,

FTI ITP Padang,

Jl. Gajahmada-Kandis-Nanggalo Padang 25143 Indonesia, telp: +627517055202.

Email: al.mtdrs@gmail.com

\section{INTRODUCTION}

In this millennial era, Quadcopter aircraft has become a trend of the world's people, whether used as a special purpose although as a hobby. The special use of Quadcopter aircraft such as military interests, the interests of mapping surveys and other purposes such as natural disaster relief [1]. Wahyuni at. al 2016 used UAV as a tool to estimate Biomass above the Land of Forest Reclamation. They found that the best model to estimate the aboveground biomass is $\mathrm{Ci} \mathrm{AGB}=0.2371 .368$ with a correlation coefficient of 0.712 $[2,3]$. The use of Quadcopter as a hobby has spawned a community of Quadcopter maniac societies, almost covering any country in the world as a Quadcopter. Quadcopter existence will become more important to take a bigger role in various purposes including business. They will be an integral part of everyday human life activities, such as from small things to greater interests such as defense and security [4].

There are still many obstacles in operating a quadcopter such as plane easy to fall; the plane is easy to hit; the battery is not durable; vulnerable to weather conditions and others. In relation to that, Quadcopter's research and development is becoming more and more developed to cover the weaknesses of the existing Quadcopter aircraft as well as to improve aircraft facilities and capabilities [5]. The Vertical Take off Landing (VTOL) Aircraft is a type of aircraft that can do take off and landing perpendicular to the earth so it can be done in a narrow place. The UAV of this type is suitable for the survey location function in a narrow area such as urban residential areas or many shrubs areas [6]. Pounds 2006 has been researching about Pilot, quad-rotor robot chassis and avionics using custom-built motor and battery off-the-shelf, into a highly reliable experimental platform. This vehicle uses the plant dynamics are tuned with mounted on-board attitude control to stabilize flight [7]. 
The process of analyzing the rotor lift force is very complex and complete. The results of this style are important, in choosing a motor for the UAV system [8]. Tao in 2016, citing an unmanned air traffic management system [9]. The purpose of his research is to: a dating system; current practice system; How do pilots use the system, and who has authority; determine what architecture is needed in a system that supports various types of aircraft.

In developing knowledge and information about Quadcopter aircraft, this study proposes to find a relationship between changes in the BLDC motor voltage source and the rotor angle velocity $(\omega)$; changes in rotor angular velocity to wind speed through the rotor $(\mathrm{v})$; changes in the rotor angle velocity to the lift rotor $(\mathrm{Ft})$; changes in wind speed to the elevator rotor; rotor thrust coefficient $(\mathrm{Ct})$. The ability of airplanes in air is based principally on; Newton's Law; Archimedes; Pascal; Bernoulli, and the law of sustainability. Newton's law describes the relationship between forces acting on objects and their movements. Archimedes' law explains the upward pressure on objects when immersed in liquid. Pascal's law states that the pressure given to the liquid is passed in all directions. Bernoulli Law explains that an increase in fluid velocity causes a decrease in pressure in the flow. The Law of Continuity shows the fact that the massa of a moving fluid will not change when it is negative [10].

Research on the Quadcopter lift and drag using the Computational Fluid Dynamics (CFD) technique was proposed [10], because wind tunnel experiments are very difficult and additional costs are more expensive. This technique shows closeness with real experiments. In principle, when the aircraft is in the air, there are four main forces acting on the plane, T thrust, D drag, lift and aircraft weight (weight W). Four aerodynamic styles in flight were discussed by George Cayley, 2008. Meanwhile, the movement of the quadcopter was like going back and forth; Left and right; up and down, influenced by variations in direction, speed and acceleration of four rotors. for quadcopter that has fixed blade parameters that can change is the speed and acceleration of the propeller angle [11].

Research on lifts and drag force of a UAV by using Computational Fluid Dynamics (CFD) technique is proposed [12], because wind tunnel experiments are very difficult and additional cost more. This technique shows a close proximity to the real experiment. In the principle, when the aircraft is on the air, there are four main forces acting on the plane, the thrust T, drag D, lift and weight of the plane (weight W). George Cayley, 2008, discusses the four aerodynamic forces in flight. Meanwhile, the quadcopter movements such as back and forth; Left and right; up and down, influenced by variations in direction, speed and acceleration of four rotors for a quadcopter that has fixed blade parameters that can change is the speed and acceleration of the propeller angle [13].

The propeller serves to transfer power by changing rotational movements into an impulse to move a vehicle like an airplane, through an air mass, by rotating two or more twin blades from the main shaft. The propeller acts as a rotating wing and produces a force that applies Bernoulli's principles and Newton's laws of motion, resulting in differences in pressure between the front and rear or top-down or left-right surfaces. The size of the knife used in the quadcopter varies depending on the size of the quadcopter and the load to be lifted by the quadcopter. Therefore to calculate how much lift and speed a quadcopter is, it is important to know the relationship between size, rotation speed and propeller lift. The relationship between measures of lift and speed such as (1) and (2) [14].

$$
T=\left(C_{t} \cdot \pi \cdot \rho \cdot r^{2} \cdot v^{2}\right) / 2
$$

On the line, Coefficient thrust $\left(\boldsymbol{C}_{t}\right)$ can be expressed as equation 7.

$$
C_{t}=2 \cdot T /\left(\pi \cdot \rho \cdot r^{2} \cdot v^{2}\right)
$$

Where: $C_{t}$ is thrust coefficient; $T$ is rotor thrust; $\pi$ is $3.14 ; \rho$ is density of air $=1.225 ; r$ is radius of blade; $v$ is air speed.

\section{RESEARCH METHOD}

In this study, empirical testing was done in the laboratory to find out the relationship amongst other things: changes in BLDC motor voltage source to rotor angle velocity $(\omega)$; changes in rotor angle velocity to wind speed through the rotor $(v)$; the change in the angular velocity of the rotor to the rotor lifts $(F t)$; changes in wind speed to rotor lift; rotor thrust coefficient $(C t)$.

To obtain the results of these measurements than required materials and equipment as follows; 1200 Kv BLDC Motor; 30 Ampere Electronic speed controller (ESC); Voltage sensor; 500 K Ohm Potentiometer; Arduino Uno Microcontroller; Mechanic stand up; LCD display; Blade propeller with radius (r) is 0.12 meter; Digital Anemometer; Digital Tachometer; Digital Strain Gauge. Implementation of this rotor 
parameter measurement is done in accordance with the block diagram as in Figure 1. The material and measurement equipment are shown as in Figure 2.

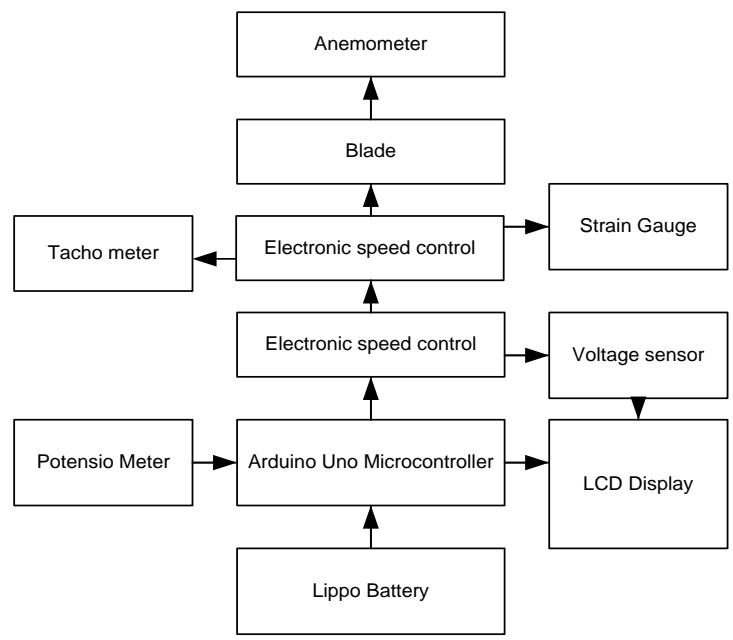

Figure 1. Block diagram of measurement system

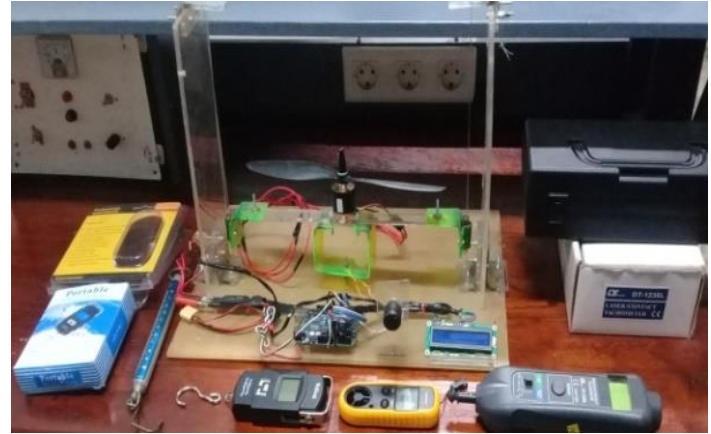

Figure 2. The material and measurement equipmen

\section{RESULTS AND ANALYSIS}

In this testing phase it can be seen that: providing sources ranging from 1 to 2 volts cannot move the propeller; by providing a voltage source between 2.26 to 2.85 volts the propeller has been able to rotate but does not yet have the power to soak itself; after being given between 2.86 until the condition of the 3 volt rotor is now floating or starting to rise. Currently the control voltage is given as 3.1 volts and the rotor has been lifted and is higher. The start of the elevator rotor is indicated by the rotor rotation speed of $3539 \mathrm{rpm}$. While the highest angle rotational speed reaches $5285 \mathrm{rpm}$ when given a 5 volt source voltage. Furthermore, the rotor parameters are tested by self-load which is added with a load of 50 grams, so that the total load becomes 215 grams and the content is shown in Table 1 .

\begin{tabular}{|c|c|c|c|}
\hline N0 & Voltage Source & Speed (rpm) & $\begin{array}{c}\text { Device } \\
\text { Condition }\end{array}$ \\
\hline 0 & 0 & 0 & stagnan \\
\hline 1 & 1 Volt & 0 & stagnan \\
\hline 2 & 2 Volt & 0 & stagnan \\
\hline 3 & 3 Volt & 3339 & stagnan \\
\hline 4 & 3,10 Volt & 3539 & stagnan \\
\hline 5 & 3,15 Volt & 3562 & cutinhalf \\
\hline 6 & 3,50 Volt & 4034 & go-up \\
\hline 7 & Volt & 4708 & go-up \\
\hline 8 & 5 Volt & 5185 & go-up \\
\hline
\end{tabular}

With a load of 215 grams, it can be seen in Table 1 that; between 1 to 3.14 volts source voltage, the rotor cannot be lifted. When given a 3.15-volt source voltage then the aircraft starts to float. Starting from the 3.25-volt source voltage and rushing up the rotor is already up and moving higher. Furthermore, by providing a total weight of 315 grams, the result of the parameter measurement is shown as in Table 3 . Table 2 shows that the rotor floats when the source voltage is given at 3.78 volts. Whereas, after the source voltage is given by 3.8 volts continues up to 5 volts, the rotor is raised and the higher.

Hereinafter, the measurement of rotor parameters with a total load of 365 grams, the results are shown in Table 3. The data in Table 4 shows that the source voltage between 1 to 3.8 volts has not been able to hold the rotor along with the load. The rotor begins to float at a given source voltage of 3.81 volts with a rotor rotation speed of $4355 \mathrm{rpm}$. By providing a voltage source of 3.82 volts to produce a rotor rotation speed of 4492-rpm rotor start moving upward, and so on the addition of source voltage up to 5 volts increase the speed of the rotor is marked with a peak rotation speed of $5079 \mathrm{rpm}$. 
Table 2. Measurement with 315-Gram Load

\begin{tabular}{|c|c|c|c|}
\hline No & Voltage source & Rotor Speed (rpm) & Device condition \\
\hline 1 & Volt & 0 & stag \\
\hline 2 & $2 \quad$ Volt & 0 & stag \\
\hline 3 & 2,26 Volt & 964 & stag \\
\hline 4 & 2,50 Volt & 2008 & stag \\
\hline 5 & Volt & 3339 & stag \\
\hline 6 & 3,77 Volt & 4317 & stag \\
\hline 7 & 3,78 Volt & 4355 & floating \\
\hline 8 & Volt & 4581 & go-up \\
\hline 9 & 5 Volt & 5079 & go-up \\
\hline
\end{tabular}

Table 3. Measurement with 365-Gram Load

\begin{tabular}{|c|c|c|c|}
\hline No. & Voltage source & Rotor Speed (rpm) & Device condition \\
\hline 1 & $1 \quad$ Volt & 0 & stag \\
\hline 2 & 2 Volt & 0 & stag \\
\hline 3 & 2,26 Volt & 964 & stag \\
\hline 4 & 2,50 Volt & 2008 & stag \\
\hline 5 & 3 Volt & 3339 & stag \\
\hline 6 & 3,80 Volt & 4419 & stag \\
\hline 7 & 3,81 Volt & 4578 & floating \\
\hline 8 & 3,82 Volt & 4492 & Go-up \\
\hline 9 & 4 Volt & 4523 & Go-up \\
\hline 10 & 5 Volt & 4944 & Go-up \\
\hline
\end{tabular}

By examining the results of the test Table 1 already with Table 3, it is directly indicated that the increase in source voltage raises the increase to the speed of rotation of the rotor. The speed of rotation of the rotor makes the air velocity through it is proportional. The air velocity through the rotor is what will generate the rotor lift, according to the concept proposed by; Newton's law; Archimedes; Pascal; Bernoulli, and the law of continuity.

To know directly the relationship between; rotation speed of the rotor with a voltage source; speed of rotation of the rotor with wind speed and the rotation speed of the rotor to the resulting thrust, then continued simultaneous testing as a further explanation. The rotor angular velocity and voltage source relationship test, the wind speed and the lift produced by the rotor are performed with stand up as Figure 3.

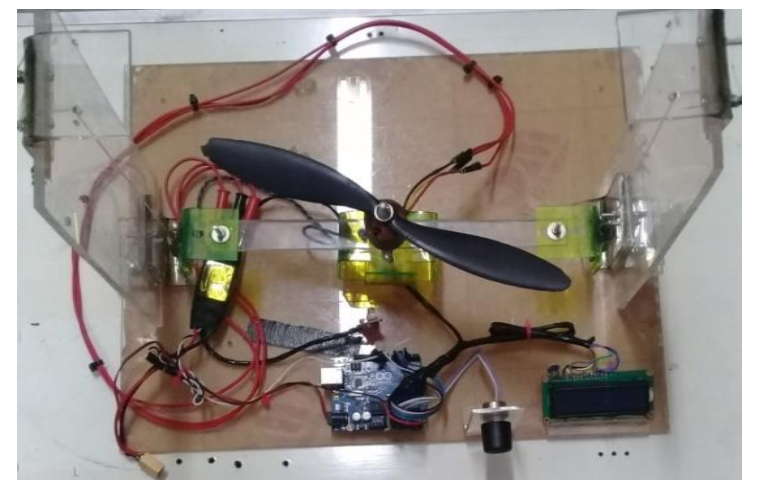

Figure 3. Rotor under testing

The preparations and test instruments in Figure 1 comprises blades with a radius of $0.0645 \mathrm{~m}$; BLDC Motor 1200Kv; Electronic speed controller (ESC); Arduino microcontroller UNO; Lithium 30 A 5 V Battery; LCD display as an indicator of the voltage source; Anemometer; Digital Tachometer and Digital strain gauge.

The results of the air velocity testing of the rotor speed are shown in the graph of Figure 4. This graph illustrates that the increase in rotor speed produces air velocity proportional to the linear trend during the change. 


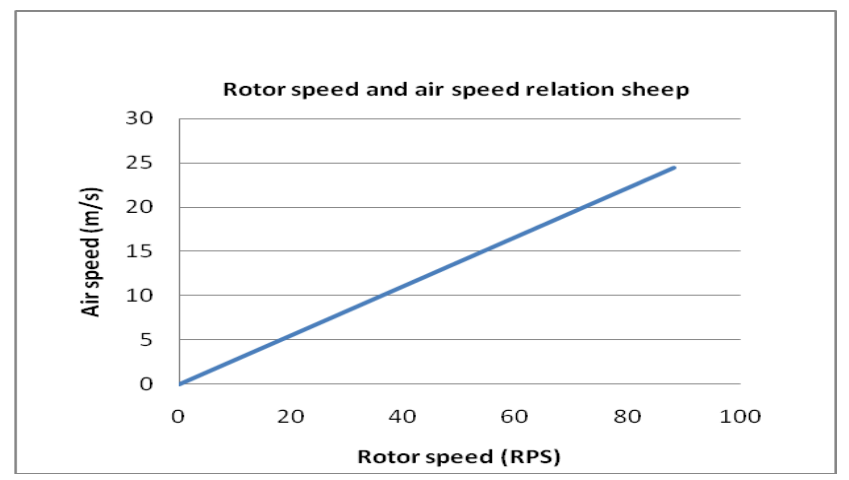

Figure 4. Rotor and air speed relationship

Measurement of the rotor lift to the change in rotation speed of the rotor angle is done by measuring instrument of the digital strain gauge and digital tachometer. The result is shown in the graph in Figure 5 . Figure 4 states that the increase in rotor speed causes an increase in the rotor thrust. the relationship of both parameters increase is not linear at all. On the graph shows that between zero to $60 \mathrm{rps}$ starts with a linear trend, between 65 up to 75 rps trend occurs bend and after that greater than 75 rps obtained linear trend back. In a non-linear condition between 65 and $75 \mathrm{rps}$, a change of thrust state is used only to elevate itself until it begins to draw the strain gauge as a measure of the rotor's lift power.

By using $1200 \mathrm{Kv} / 5$ Volt BLDC motor and blade which is has a radius $\mathrm{r} 0.12 \mathrm{~m}$, and then according to equation $C_{t}=2 . T /\left(\pi \cdot \rho \cdot r^{2} \cdot v^{2}\right)$ is obtained by the thrust coefficient $\left(\mathrm{C}_{\mathrm{t}}\right)$ according to the wind speed as shown in the Figure 5. Where: $C_{t}$ is thrust coefficient; $T$ is rotor thrust; $\pi$ is $3.14 ; \rho$ is the density of air $=1.225 ; r$ is the radius of the blade; $v$ is air speed.

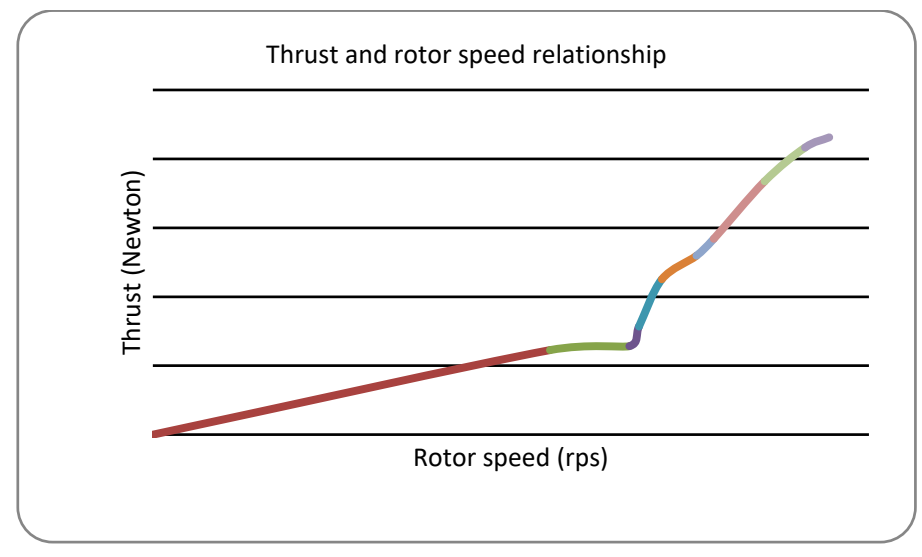

Figure 5. A thrust and rotor speed selationship

Table 4. Average of Ct From Thrust and Air Speed v

\begin{tabular}{cccccc}
\hline Total thrust (Newton & Airspeed $(\mathrm{m} / \mathrm{s})$ & $\pi$ & $\rho$ & radius $\mathrm{r}(\mathrm{m})$ & Coefficient Thrust $(\mathrm{Ct})$ \\
\hline 0 & 0 & 0 & 0 & 0 & 0 \\
1.225 & 5.5 & 3.14 & 1.225 & 0.12 & 1.462219 \\
1.225 & 5.9 & 3.14 & 1.225 & 0.12 & 1.270673 \\
1.2838 & 6 & 3.14 & 1.225 & 0.12 & 1.287646 \\
1.568 & 6.2 & 3.14 & 1.225 & 0.12 & 1.47287 \\
2.254 & 6.5 & 3.14 & 1.225 & 0.12 & 1.926322 \\
2.597 & 7 & 3.14 & 1.225 & 0.12 & 1.913717 \\
2.842 & 7.5 & 3.14 & 1.225 & 0.12 & 1.82433 \\
3.675 & 8 & 3.14 & 1.225 & 0.12 & 2.073381 \\
4.165 & 8.5 & 3.14 & 1.225 & 0.12 & 2.081512 \\
4.312 & 9 & 3.14 & 1.225 & 0.12 & 1.922186 \\
\multicolumn{5}{c}{ Total Ct } \\
Average Ct & & & 17.23486 \\
& \multicolumn{5}{c}{}
\end{tabular}


After measuring more than 20 times, the average measurement value as shown in Table 4 . Table 4 gives information that the conversion of wind speed generated by the rotor produces a comparable thrust. Convertible results are influenced by many factors such as; the size and shape of the blade; earth gravitation; density of air; and constant changes. With blade conditions as described earlier and at an ambient temperature of $27^{\circ}$ Celsius the coefficient of this rotor $(\mathrm{Ct})$ of 1.723 is obtained.

\section{CONCLUSION}

Provide After doing the measurement, testing and analysis of data then it can be concluded as follows. The increase in the rotation speed of the rotor is proportional to the increase of the source voltage applied to the BLDC motor and the increase is not always linear as long as the voltage changes from 1 to 5 volts. The linear range occurs between 2.5 to 4 volts. The relationship between rotation speed and the resulting airspeed is proportional to the trend of linear.

The relationship between lift powers produced with rotational speed is not comparable. The nonlinearity occurs when the root is relieved of the weight of oneself and proceeds to start pulling the strain gauge when the rotation speed reaches around $65 \mathrm{rps}$. Once the rotation speed of the rotor is able to generate lift to reach 1.5 Newton then increase the endurance rotor has sharp increasingly. Using a BLDC motor which is specifications as $1200 \mathrm{Kv}, 5$ Volt and 30 Ampere; blade with a radius of $\mathrm{r} 0.12 \mathrm{~m}$; at a temperature of about $27^{\circ} \mathrm{C}$; in the condition is no other wind currents then obtained the thrust coefficient $(C t)$ of 1.732 .

\section{ACKNOWLEDGEMENTS}

I would like to thank the Ministry of Research, Technology and Higher Education of Republic Indonesia and Institut Teknologi Padang in supporting this research.

\section{REFERENCES}

[1] Al, Arfita Yuana Dewi, Joko Ade Saputro, "Quadcopter capability development for additional low voltage distribution network location tracking”, International conference of aplied science on emngineering, business, linguistics and information technology, Padang-Indonesia, October 14 th, 2017.

[2] S. Wahyuni, I. N. Surati Jaya, and N. Puspaningsih, "Model for Estimating Above Ground Biomass of Reclamation Forest using Unmanned Aerial Vehicles," Indonesian Journal of Electrical Engineering and Computer Science (IJEECS), 2016. vol. 4, p. 586.

[3] H. Muis, I. N. S. Jaya, M. B. Saleh, and K. Murtilakono, "Information Required for Estimating The Indicator of Forest Reclamation Success in Ex Coal-Mining Area," Indonesian Journal of Electrical Engineering and Computer Science (IJEECS). 2016; vol. 3, pp. 182-193.

[4] Parag Parihar, Priyanshu Bhawsar, Piyush Hargod, "Design \& Development Analysis of Quadcopter", COMPUSOFT, An international journal of advanced computer technology, 5 (6), June-2016 (Volume- V, Issue-VI

[5] Oyvind Magnussen, Morten Ottestad, Geir Hovland, "Multicopter Design Optimization and Validation", Modeling, Identification and Control, 2015, Vol. 36, No. 2, pp. 67-79, ISSN 1890-1328

[6] A. Al, "An Improved a Quadcopter Capability for Forestall Bump with the Ultrasonic HC SR04 Proximity Sensor Design," International Conference on Technology, Innovation, and Society (ICTIS) 2016.

[7] Pounds, P., Mahony, R., and Corke, P., "Modelling and Control of a Quad-Rotor Robot," In Proceedings of the Australasian Conference on Robotics and Automation, 2006.

[8] Yamika Patel, Anant Gaurav, Krovvidi Srinivas, Yamal Singh, "A Review on Design and Analysis of the propeller used in UAV". International Journal of Advanced Production and Industrial Engineering, 2016 IJAPIE-SI-IDCM 605 (2017) 20-23. Available online at www.ijapie.org

[9] Tao Jiang, Jared Geller, Daiheng Ni, John Collura," Unmanned Aircraft System traffic management: Concept of operation and system architecture," International Journal of Transportation Science and Technology 5 (2016) $123-135$.

[10] Giuseppe Guido, Vincenzo Gallelli, Daniele Rogano, Alessandro Vitale,"Evaluating the accuracy of vehicle tracking data obtained from Unmanned Aerial Vehicles" International Journal of Transportation Science and Technology 2016 V-5 pp.136-151.

[11] Adam Babinec a, Jiri Apeltauer, "On accuracy of position estimation from aerial imagery captured by low -flying UAVs", International Journal of Transportation Science and Technology, 2016, v.5 pp. 152-166.

[12] S. Patel Karana, B. Patel Saumil, "CFD Analysis of an Aero foil", International Journal of Engineering Research, 2014 Volume No.3, Issue No.3, pp: 154-158.

[13] Krajn'1k, T, Von'asek, V, Fi`ser, D \& Faigl, J 2011, AR-Drone as a Platform for Robotic Research, The Gerstner Laboratory for Intelligent Decision Making and Control Department of Cybernetics, Faculty of Electrical Engineering Czech Technical University, Prague.

[14] Brandt, J.B. and Selig, M.S., "Propeller Performance Data at Low Reynolds Numbers," 49th AIAA Aerospace Sciences Meeting, AIAA Paper 2011-1255, Orlando, FL, January 2011. 